\title{
Idosos hipertensos na atenção básica em saúde: discursos e identidades
}

\author{
Hypetensiveddaly peadein pinary hedthcare dscarsesandidatities
}

\section{Resumo}

O objetivo da pesquisa foi conhecer e compreender como os sujeitos se reconhecem na posição de idosos, como se percebem hipertensos e como experienciam o tratamento anti-hipertensivo. Pesquisa de abordagem qualitativa, descritiva e exploratória, realizada em unidade de saúde da família de Dourados, MS. Os aportes teóricos da análise foram os Estudos Culturais. Foram entrevistados dez idosos hipertensos, sendo dois homens e oito mulheres. Os idosos tinham entre 60 e 88 anos, sendo cinco viúvas, e todos com ensino fundamental incompleto. Os processos identitários estão vinculados a gênero, estado marital e relação com as gerações. O envelhecimento parece se concretizar quando não se sentem produtivos. A hipertensão e o tratamento decorrente estão entremeados nos processos de subjetivação dos idosos, sendo que o uso de medicamentos para alguns parece estar incorporado ao cotidiano, porém outros relataram aversão. Desse modo, os significados da velhice contemporânea pertencem a um período singular e são integrantes de processos históricos mais amplos e complexos.

\section{Abstract}

The aim was to know and understand how subjects recognize themselves in the position of older men and women, how they perceive themselves with hypertension and high blood pressure, and how they experience the anti-hypertensive treatment. It is a qualitative, descriptive and exploratory research approach, performed in family health units, in Dourados. The theoretical framework of analysis was the Cultural Studies. We interviewed ten elderly hypertensive patients, two men and eight women, aged 60-88 years, five widows, and all with elementary education. The processes are linked to gender identity, marital status and relationship with the generations. Aging seems to be realized when they are not productive. Hypertension treatment and due process are interspersed in the subjectivity of the elderly, and drug use for some seems to be incorporated into everyday life, but others reported aversion. Thus, the contemporary meanings of old age belong to a unique period and are members of larger historical processes and complex.
Rogério Dias Renovato' Maria Helena Salgado Bagnato ${ }^{2}$
Palavras-chave: Saúde do idoso. Atenção primária em saúde. Hipertensão. Uso de medicamentos.

Key words: Aged health Primary health care. Hypertension. Drug use.

Curso de Enfermagem. Universidade Estadual de Mato Grosso do Sul. Dourados, MS, Brasil.

2 Faculdade de Educação. Universidade Estadual de Campinas. Campinas, SP, Brasil.

Financiamento: pesquisa financiada pela FUNDECT.

Correspondência / Correspondence

Rogério Dias Renovato

Rua Hilda Bergo Duarte, 296

79806-020 Dourados, MS, Brasil

E-mail rrenovato@uol.com.br 


\section{INTRODUÇÃO}

A hipertensão arterial sistêmica é uma condição crônica e um dos principais fatores de risco para as doenças cardiovasculares, dentre as quais a doença arterial coronariana e o acidente vascular encefálico. As Diretrizes Brasileiras de Hipertensão Arterial Sistêmica relatam que as doenças cardiovasculares, desde a década de 1960, superaram as doenças infecciosas como a primeira causa de mortalidade no Brasil. Ainda hoje, as doenças cardiovasculares representam 29,4\% dos óbitos no Brasil. ${ }^{1}$

A hipertensão em geral é assintomática, o que pode dificultar o diagnóstico mais precoce e a prescrição de tratamento adequado. Além disso, a baixa adesão ao tratamento por parte dos pacientes constitui um dos fatores de hipertensão não controlada. Os idosos brasileiros apresentam elevada prevalência de hipertensão, em torno de $65 \%$, e o controle da pressão arterial nessa população requer, além da avaliação do risco cardiovascular, a verificação de comorbidades e o uso de medicamentos. ${ }^{2}$

Como qualquer processo fisiopatológico, essa doença também é envolta de outras dimensões, como as experiências, vivências e significados percebidos pelos pacientes e também pelos profissionais de saúde. Pesquisas qualitativas, apesar do número ainda restrito, têm procurado explorar os sentidos atribuídos à hipertensão, sua etiologia, diagnóstico e tratamentos. E, assim, abordagens interpretativas podem auxiliar na compreensão da constituição das subjetividades dos hipertensos e da não-adesão ao tratamento, quer farmacológico, como não-farmacológico..$^{3-5}$

Desse modo, a aproximação com o conceito de identidade dos Estudos Culturais pode contribuir para esta pesquisa. De acordo com esse campo teórico, a produção de sujeitos, a partir de diferentes práticas simbólicas, está sempre situada em um determinado espaço-tempo. A identidade do idoso pode ser constituída em uma rede discursiva; logo, as identidades podem ser produtos do discurso e da cultura. Tanto a identidade como a diferença são ativamente produzidas. As identidades dos idosos com hipertensão podem ser fabricadas no contexto de relações sociais e culturais. ${ }^{6}$

O objetivo do estudo foi conhecer e compreender como os sujeitos se reconhecem na posição de idosos, como se percebem hipertensos e como experienciam o tratamento anti-hipertensivo. Em suma, como eles assumem determinados discursos e identidades no emaranhado de experiências acerca do envelhecimento e adoecimento.

\section{METODOLOGIA}

Pesquisa de abordagem qualitativa, descritiva e exploratória. O estudo foi realizado em Unidade de Saúde da Família do Cuiabazinho, em Dourados-MS, no segundo semestre de 2006. Essa unidade, também chamada Equipe 15, no período da pesquisa apresentava 3.942 indivíduos adscritos, 984 famílias, 280 hipertensos, 77 diabéticos e 23 gestantes.

Os sujeitos da pesquisa foram dez idosos hipertensos cadastrados na unidade e sob acompanhamento regular há pelo menos um ano. Os critérios de exclusão foram os indivíduos incapazes de se comunicar, quer por razão de comprometimento cognitivo ou outros motivos, e aqueles que não consentiram em participar da pesquisa. Os participantes assinaram Termo de Consentimento Livre e Esclarecido.

A abordagem inicial se deu com a enfermeira da unidade, e o contato com os sujeitos foi intermediado por agentes comunitários da saúde. Os idosos hipertensos foram entrevistados em seus domicílios utilizando-se roteiro contendo questões fechadas e abertas. As entrevistas de ambas as etapas foram gravadas e transcritas.

A amostra foi do tipo intencional, sendo entrevistados dez idosos hipertensos. Além das entrevistas, foi realizado o diário de campo. Os idosos foram caracterizados nas seguintes categorias: procedência, idade, gênero, situação trabalhista, situação anterior, escolaridade, estado marital, núcleo domiciliar e presença de algum membro familiar durante a entrevista. Os 
nomes atribuídos aos entrevistados são fictícios. As entrevistas foram analisadas por meio da análise de conteúdo.

Para fomentar as análises, tecemos aproximações com o campo dos Estudos Culturais, mais especificamente, as perspectivas teóricas de Stuart Hall e Michel Foucault, tendo as seguintes concepções norteadoras: a cultura percorre as várias dimensões da vida e pode dimensionar as significações que somos capazes de atribuir aos acontecimentos vivenciados; ${ }^{7}$ a cultura é um campo de lutas pela significação, envolvendo vários grupos e sujeitos sociais; os processos constitutivos de significação da cultura são linguísticos e permeados por relações de poder dispersas, de caráter não apenas repressivo, mas eminentemente produtivo; os sujeitos assumem determinadas posições de forma incompleta e não-permanente, podendo ou não se identificar com determinados discursos que operam dentro de dinâmicas culturais envoltas por processos de resistência, de negociação e acomodação. ${ }^{8}$

Esta pesquisa está vinculada ao projeto "Análise das práticas educativas em saúde na hipertensão sob a ótica da vulnerabilidade", que foi enviado ao Comitê de Ética em Pesquisa da Faculdade de Ciências Médicas da Unicamp, sendo aprovado conforme parecer 255/2006, CAAE 0188.0.146.000-6.

\section{RESULTADOS E DISCUSSÃO}

Os sujeitos da pesquisa foram oito mulheres e dois homens. A idade variou de 60 a 88 anos. Em geral, os idosos eram migrantes de outros estados: quatro vieram do Rio Grande do Sul, um de Minas Gerais, um da Bahia e um de São Paulo. Cinco eram viúvas e residiam com seus filhos e netos. Os idosos relataram ter de dois a 12 filhos, e apresentavam ensino fundamental incompleto. Quanto à ocupação, os idosos relataram as seguintes: dona de casa, ajudante de pedreiro, costureira, motorista e comerciária.

No primeiro momento, apresentamos alguns elementos que ressoaram nas entrevistas, como o nível de escolaridade, a posição ocupada no espaço familiar e as representações sobre envelhecimento. Na segunda parte dos resultados, procuramos discorrer sobre os discursos acerca da hipertensão, e como o idoso vivencia sua condição crônica, bem como o tratamento farmacológico e seus enfrentamentos.

\section{A escolaridade dos idosos}

"Eu não tenho leitura, você não vê a minha letra?" - a fala da Sra. Gabriela ecoou nas demais entrevistas. Em geral, todos apresentavam nível de escolaridade baixo. Como isso pode, então, contribuir nas identidades desses idosos? Quais as brechas utilizadas para enfrentar a pouca leitura? A história da Sra. Gabriela exemplifica bem a situação. Seu pai não permitia que ela aprendesse, e como tinha muita vontade de saber ler e escrever, então a alternativa foi pedir a seu irmão ajuda para aprender a escrever seu nome.

A baixa escolaridade dos idosos brasileiros tem sido relatada por vários pesquisadores. 'Sem tentar encontrar causalidades, é possível verificar que a infância na zona rural, as relações de poder e de gênero, o envolvimento da família em todo o serviço de casa e das propriedades podem ter dificultado o acesso ao ensino formal.

Mesmo quando se mudaram para as cidades, a possibilidade de obter a educação era obstruída pelos afazeres de casa, pela criação dos filhos, pela necessidade de sustentar a casa. Enfim, a baixa escolaridade parece não apenas interferir em como esses idosos entendem as informações em saúde, mas também como eles se situam em uma sociedade cuja ausência de escolaridade pode classificar, excluir e dificultar o acesso desse grupo a seus direitos.

Casados/as e viúvas, donas de casa e cuidadoras de netos

Os sujeitos da pesquisa eram mulheres e homens casados. Em geral eram uniões de longa data, com trinta a quarenta anos em média. Mesmo o Sr. Fábio, em seu segundo casamento, já apresentava duas décadas de 
união. Ao casamento, outras relações são e foram estabelecidas, como a criação de filhos e o cuidado da casa, pela mulher, e o sustento financeiro, pelo homem. As famílias desses idosos são numerosas com vários filhos, netos e até bisnetos. São laços que se configuram em relações de poder, como relatou Sra. Erondina:

"[...] en ganhei a liberdade depois que o meu marido faleceu, porque en não podia ter uma prosa com a vizinha, eu não podia receber ninguém que nem boje, nada disso podia. Então, en ganbei liberdade depois que meu finado marido faleceu. Eu não tinha liberdade para viajar."

A naturalização das atribuições do esposo e da esposa se configuram nas falas desses idosos, mas foi possível perceber também outros formatos contemporâneos, como o caso do Sr. Fábio, que hoje cuida da casa, enquanto sua esposa trabalha fora. Apesar de se sentir um pouco incomodado, é possível atentar para as transições potenciais de algo estabelecido e que hoje passa por mudanças.

No entanto, o trabalho da casa ainda é assumido pela mulher idosa. Ainda cozinham, passam roupa, limpam a casa. Mesmo aposentadas ou pensionistas, ainda casadas, suas atividades de donas de casa permanecem com algumas modificações. Agora, encontram ajuda nas diaristas ou empregadas domésticas, que realizam atividades mais pesadas. Com exceção do Sr. Fábio, que assumiu esses encargos, as mulheres idosas arroladas nesta pesquisa continuam como donas de casa e cuidadoras - neste caso, dos netos trazidos pelos filhos e filhas.

A proximidade física com os filhos, que residem no mesmo bairro, ou até moram nos fundos da casa, estabelecem espaços de cuidado, em que o idoso passa a partilhar da criação de seus netos e bisnetos. Seu auxilio pode se resumir a uma tarde da semana, ou até todo um período do dia. Se são mulheres com tempo livre, e prontas para o cuidar, assumem mais uma vez o papel de cuidadoras. E, assim, participam ativamente da criação de outra geração, e em alguns casos, o cuidado se estende também ao suporte financeiro, já que recebem mensalmente sua aposentadoria ou pensão.
Em pesquisa realizada com idosos sobre as percepções de gênero, os relatos parecem convergir com os achados deste estudo, visto que as atividades de cuidado exercidas pelas idosas constituem a base para a construção de suas identidades. ${ }^{10} \mathrm{O}$ papel de cuidadoras pode refletir subjetividades naturalizadas de gênero, encontrando ressonâncias também na fase da velhice, mas não sob uma perspectiva binarizada, e sim envolta por processos múltiplos e provenientes de experiências ao longo de suas vidas.

Verificamos, portanto, que são várias as identidades, são descentradas, são plurais. Como podemos ver neste breve relato, são idosos e idosas, são avós, são cuidadoras, são esposas e esposos, são mães e pais:11

E o envelhecimento? "Tem que ir remando, não pode parar 0 barquinho".

Apesar da delimitação arbitrária da faixa etária do envelhecimento, essa etapa da vida apresenta várias representações. ${ }^{12}$ Foi possível perceber, entretanto, nas falas dos idosos, a relação da velhice com a impossibilidade de fazer as tarefas diárias. O envelhecimento parece ainda se relacionar às limitações físicas, como a dificuldade de locomoção. A construção social e cultural do envelhecimento da sociedade ocidental contemporânea ainda contém discursos que envolvem o medo de adoecer, empobrecer e morrer diante da instabilidade e das mudanças nas estruturas familiares, além de estar associada com a dependência e a incapacidade. ${ }^{13}$

Esses achados encontram ressonâncias na fala do Sr. Fábio, que atribui a essa etapa da vida algumas características positivas, dentre elas a somatória de experiências vividas. Ao mesmo tempo, relata suas limitações, e finaliza afirmando ser sua rotina muito diferente na atualidade. No passado, fazia tudo com mais rapidez e agilidade, mas ressalta que, se tivesse um emprego, gostaria de retornar a esse tipo de vida.

Estudo realizado com homens idosos sobre o envelhecimento reforça o vínculo simbólico entre corpo e velhice. A fraqueza e a força física 
constituem elementos que delimitam a fronteira identitária do idoso. Segundo as falas desses homens, a disposição física e o vigor podem demonstrar que a juventude ainda se faz presente, mesmo que seu corpo sinalize algumas limitações. ${ }^{14}$

O envelhecimento, portanto, parece ser percebido somente quando o sujeito deixa de ser produtivo. Ao idoso esse processo de decadência e debilidade física expõe sua fragilidade e a finitude que dialoga por meio de um jogo de estranhamento e descoberta: ${ }^{15}$

"[...] eu não me acho velha, mas en não consigo trabalhar como trabalhava antes." (Sra. Erondina)

"[..] eu não tenho mais aquela energia, nem que eu queira fazer en não dou conta. Se eu vou fazer, passo um pouco da medida, já fico muito cansada. Eu acho que é ruim porque en tenho que fazer. Se eu não puder fazer, eu tenho que pagar alguém.” (Sra. Luzia)

"[...] sinto canseira, fadiga, às vezes, quero sair e ai a minha perna está cansada. Eu acho que isso não podia acontecer." (Sra. Marieta)

Quem de fato são o idoso e a idosa? Apesar do processo de nomeação legal que posiciona e classifica as pessoas como idosas, elas mesmas não querem se posicionar como velhas ou idosas; ao invés disso, o velho quer passar a ser o outro:

"[...] às vezes en fico, assim, pensando: eu já tenho setenta anos e tem velhinhos com setenta e são tão desanimados. Eu graças a Deus, eu tenho ânimo. Deus me dá forças de fazer oração pela minha família." (Sra. Marieta)

O envelhecimento não demarca as subjetividades apenas pelas limitações corporais, pelas dores, pela maior incidência de doenças antes não acometidas, mas também pelo fato de que, ao se tornar velho, sua força de trabalho é reduzida. Ser velho parece implicar não poder mais trabalhar com tanta intensidade. Como relata a Sra. Gabriela, a velhice está atrelada à aparente preguiça, à vontade de não trabalhar. Para o Sr. Daniel, as estratégias de resistência incluem continuar fazendo alguma atividade, exercitar seu corpo, mostrar-se útil: "[...] continuo carpindo o quintal, isso não abro mão”. (Sr. Daniel)
Idosos/as com hipertensão: vivências

sobre a doença e o tratamento

Como a hipertensão é uma condição crônica, isto é, acompanha uma parte da vida dessas pessoas, novos conhecimentos, situações e posturas são apresentados, e muitas vezes exigidos. Ao ser idoso com hipertensão são atribuídos comportamentos que não se restringem ao campo biomédico, mas se inserem em práticas sociais, culturais e discursivas. Assim como em relação ao envelhecimento, a identidade do ser humano com hipertensão passa a ser constituída em uma rede discursiva, e não em substâncias fixas e estáticas.

Em relação à hipertensão, mesmo sendo considerada doença silenciosa, os idosos relataram com clareza que percebem a elevação da pressão arterial. A doença sinaliza e comprova sua presença no corpo que envelhece, e assim essas impressões sensíveis produzidas pelo mal-estar físico ou psíquico convergem para as representações sobre o adoecimento: ${ }^{16}$

"[...] eu sinto dor de cabeşa quando ela está alta. A cabeça começa a doer." (Sra. Gabriela)

“[... eu sinto um aperto no peito.” (Sra. Luzia)

Em relação ao tratamento não-farmacológico, os idosos atribuíram papel de destaque à alimentação. A preocupação com a dieta alimentar, a restrição às gorduras na alimentação, a redução da quantidade, foram medidas relatadas pelos sujeitos da pesquisa:

"[...] minha comida, menos sal, menos gordura. Não como fritura." (Sra. Sofia)

"[... jantar é difícil. As vezes tomo um copo de leite, e se tem fruta, em geral, não tem fruta todos os dias. Então, quando tem fruta eu faço um suco, uma vitamina." (Sra. Luqia)

"[...] A gente não come fritura. Não come muito salgado. Não toma bebida de álcool." (Sra. Erondina)

Em pesquisa realizada com idosos assistidos pela atenção primária à saúde, a importância do cuidado com a alimentação também foi relatada, 
e seus discursos sugeriram que a comida fazia parte de um plano terapêutico pessoal e interligado com os seus problemas de saúde. ${ }^{17}$ Porém, mesmo com todas essas informações que moldam o cuidado de si como um dever, muitas vezes até moral, foi possível perceber que alguns idosos não seguem as prescrições nutricionais:

$$
\begin{aligned}
& \text { "[...] daquilo que en gosto, como de tudo." (Sr. Daniel) } \\
& \text { "[...] não faço dieta nenbuma, sou muito comilona. } \\
& \text { Estou acima do peso. Faz. um mês e pouco estava com } \\
& 83 \text { quilos." (Sra. Marieta) }
\end{aligned}
$$

Já em relação à terapêutica medicamentosa, os significados atribuídos são naturais, conforme relataram alguns idosos, algo incorporado tranquilamente à sua rotina diária. Em geral, não demonstraram discursos contrários à adesão ao tratamento:

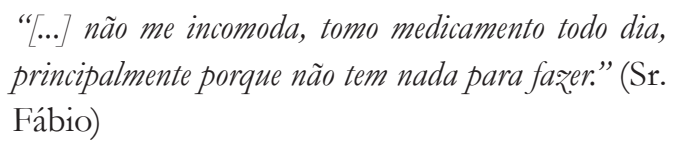

"[...] não me incomoda, tomo medicamento todo dia, principalmente porque não tem nada para fazere.” (Sr. Fábio)

"[...] porque é uma coisa que tem que fazer todo dia. Não me prejudica não.” (Sra. Gabriela)

O processo de naturalização do uso de medicamentos pode ser visto como o passaporte para a prevenção dos males decorrentes dessa condição crônica, bem como o artefato químico que estabelece a normalidade. Nesse processo estão implicadas representações do normal e do patológico, imbricados em uma rede de significados e vivências que mesclam o saber biomédico e os saberes adquiridos ao longo da vida.

Em outra pesquisa, esses mesmos achados parecem se reproduzir, como a naturalização do tratamento medicamentoso e a relação de obediência ao tratamento prescrito. ${ }^{18}$ Em geral, muitos pacientes relatam serem cumpridores do tratamento, denotando o sentido de obrigação. Com isso, o uso de medicamentos e seus discursos de obediência ao tratamento prescrito vão se sedimentando com o tempo, a partir das experiências construídas social e culturalmente nesses microespaços. ${ }^{19}$
Por outro lado, os medicamentos podem ser vistos como um mal necessário. ${ }^{5}$ Tanto para a Sra. Cláudia, como para a Sra. Luzia, o uso de medicamentos não é aprazível. Sua aversão à medicação encontra ressonância em outros estudos, e os idosos preferem evitar ao máximo seu uso, não somente devido à possibilidade de efeitos colaterais, como também pelo medo da dependência, do estigma e da perda de autonomia: ${ }^{20}$

"Eu vou falar com a verdade, eu se fosse para mim não tomar, eu não tomaria (Sra. Luzia)".

Para a Sra. Luzia, a justificativa de sua aversão se refere às experiências de outras possibilidades terapêuticas em detrimento das limitações do tratamento com medicamentos alopáticos:

"Porque eu acho assim, que às vežes você toma um
remédio forte para uma coisa, ataca a outra. E, porque
minha mãe, daquelas antigas, só tomava remédios
caseiros. E morreu com quase 70 anos." (Sra. Luzia)

Os idosos hipertensos deste estudo apresentam o quadro de hipertensão há alguns anos, como a Sra. Erondina, que sabe ser hipertensa há nove anos, o que levou a uma somatória de experiências negativas com os medicamentos. Contudo, tais experiências pareceram não interferir na adesão ao tratamento relatada na maioria das falas.

Para a Sra. Gabriela, a tosse seca provocada pelo captopril foi resolvida pela troca por um outro que não provocava esse efeito adverso. Também relatou a sonolência provocada pela amitriptilina, o que levou a tomar esse medicamento apenas ao deitar. E, por fim, lembrou-se da úlcera gástrica provocada pelo uso do diclofenaco.

Outras experiências ruins foram relatadas como: dor no estômago causada pelo antibiótico, dor no estômago decorrente do uso de metformina e ruborização da face, como consequência da ingestão de nifedipina. Como se pode ver, os medicamentos podem trazer efeitos ruins àquele que o ingere. Essa dupla possibilidade pode ser encontrada nas falas dos hipertensos, que não escondem sua preocupação quanto aos efeitos colaterais e, por outro lado, temos aqueles que desconhecem esse lado perigoso do medicamento. 
Nesta pesquisa, encontramos idosas que declararam não cumprir adequadamente $\mathrm{O}$ tratamento prescrito:

"[...] isso acontece sim, aí eu passo aquele dia sem e no outro dia, eu tomo.” (Sra. Erondina)

"[...] eu esqueço, só sou esquecida, mas não me incomoda." (Sra. Marieta)

Essa mesma idosa, todavia, demonstra medo e apreensão quanto à possibilidade de faltar o medicamento para a ansiedade:

"Eu até fico ansiada porque quando está acabando, eu já mando fazer outro para não faltar. Isso aí eu cuido." (Sra. Marieta)

A construção discursiva das idosas acima fortalece a perspectiva de que a adesão e a não-adesão ao tratamento medicamentoso podem se configurar em fenômenos sociais e culturais, entremeados de significados e representações sobre a finalidade e utilidade desses tratamentos em suas vidas diárias. ${ }^{21} \mathrm{No}$ entanto, as práticas discursivas que alardeiam o uso racional de medicamentos acabam criando elementos classificatórios e, como consequência marginalizam aqueles que não se encaixam no bom comportamento.

Com base nas vivências dos idosos sobre medicação, também se percebeu hierarquia entre os medicamentos. ${ }^{22}$ Para a Sra. Josefina, não pode faltar de forma alguma o medicamento para o controle dos nervos, enquanto o medicamento da pressão, ela relatou que ocasionalmente se esquece de tomar. Desse modo, alguns medicamentos são mais importantes que os outros, ou são mais fortes. Alguns são reservados para as doenças mais graves e requerem mais cuidados em sua utilização. Outros são do dia a dia. São os medicamentos para alívio dos sintomas menores. Portanto, conforme os sentidos que cada idoso tem sobre o medicamento, sua experiência de doença, os medicamentos são valorados, e sua importância assume particularidades.

E, por fim, os idosos relataram com bastante facilidade os nomes dos fármacos e a posologia.
Todavia, esses resultados não foram verificados em pesquisa sobre a implementação do acompanhamento farmacoterapêutico de idosos hipertensos, sendo verificado que os sujeitos tiveram dificuldade em informar o nome do medicamento, a frequência, a dose, a indicação terapêutica e algum efeito colateral. ${ }^{23}$

Sendo assim, os significados que os medicamentos possuem para cada usuário reforçam o caráter performativo desses processos identitários que se constroem historicamente. Se o uso de medicamentos assume tamanha importância para aquele idoso, a ponto de ser considerado o mantenedor de sua vida, do equilíbrio de seu corpo, um modo eficaz de prevenção de problemas graves, o cumprimento das prescrições de medicamentos assume o papel de lei.

No relato da Sra. Almerinda, que apresenta problemas de coração há mais de 40 anos e já foi submetida a intervenções cirúrgicas, o uso de medicamentos, mesmo que mais complexo, já que ela toma oito, foi algo incorporado ao longo de sua vida

"Eu já sou acostumada, eu levanto de manhã, tomo men café, tomo meu remédio, e às dez horas dá outro horário para mim tomar as pilulas. Eu tomo e assim por diante. Não tem problema." (Sra. Almerinda)

Suas experiências com a medicação podem ser evidenciadas nos relatos sobre medicamentos que ficaram no passado, em sua memória medicamentosa. Para a Sra. Almerinda, os nomes dos antigos remédios ainda estão presentes em suas lembranças. São nomes comerciais, de nomenclaturas complicadas, bem como os nomes dos fármacos. O cuidado para prevenir qualquer possibilidade de esquecimento é mostrado em seu discurso:

"[...] olha uma ver, que eu deitei, e en lembrei que não tinha tomado o remédio. Mas na minha vida nunca, nunca, eu não sei por que aconteceu isso. Mas quando eu fui deitar, eu lembrei de não ter tomado o remédio. Ai eu levantei e fui tomar meu remédio." (Sra. Almerinda) 
Desse modo, o que se espera dos idosos é o governo de si, de suas condutas e, no caso dos medicamentos, que esses pacientes sejam capazes de assumir a responsabilidade por seu uso, adotando atitudes pró-ativas e alcançando posturas positivas. Desse modo, o emprego de medicamentos pelo idoso pode assumir questões morais, tanto em relação ao uso excessivo ou à não-utilização, que implicam riscos para o usuário. Esses desequilíbrios podem ser práticas desviantes, que passam a classificar esses seres humanos como irresponsáveis e incapazes de cuidar de suas próprias vidas. ${ }^{24}$

\section{Limitações do estudo}

Os dados encontrados referem-se a essa amostra de idosos inseridos em um contexto particular e singular. Outros estudos são necessários para ampliar a compreensão dos processos identitários e de experiências desses sujeitos em relação ao envelhecimento e à hipertensão.

\section{CONSIDERAÇÕES FINAIS}

Os significados da velhice contemporânea pertencem a um período singular e são integrantes de processos históricos mais amplos e complexos, que interpelam esses sujeitos a assumirem posições de homens idosos e mulheres idosas, construídos ao longo de discursos e diálogos que circulam socialmente. Assim, ao demarcar

\section{REFERÊNCIAS}

1. Sociedade Brasileira de Hipertensão. Diretrizes Brasileiras de Hipertensão VI. Ver.Bras.Hipertens 2010; jan. marc 17(1): 8-11.

2. Brasil. Ministério da Saúde. Secretaria de Atenção à Saúde. Departamento de Atenção Básica. Hipertensão arterial sistêmica para o Sistema Único de Saúde / Ministério da Saúde, Secretaria de Atenção à Saúde, Departamento de Atenção Básica. Brasília: Ministério da Saúde; 2006.

3. Benson J, Britten N. What effects do patients feel from their antihypertensive tablets and how do they as fronteiras identitárias da velhice, algumas implicações aparecem: o que fica dentro desse território e o que fica fora.

Nesta pesquisa, evidenciamos processos identitários vinculados ao gênero, ao estado marital, na relação com as gerações, ou seja, com filhos e netos. Em algumas situações, percebemos permanências; em outras, rupturas. O envelhecimento para esse grupo parece se concretizar quando não se sentem produtivos, ou com mais dificuldades de realizar atividades diárias.

A hipertensão e o tratamento decorrente estão entremeados nos processos de subjetivação dos idosos, sendo que o uso de medicamentos para alguns parece estar incorporado ao cotidiano, não apresentando dificuldade em relatar os nomes das substâncias ativas, nem expressar as reações adversas vivenciadas. Por outro lado, alguns idosos relataram aversão, sendo a terapêutica medicamentosa considerada um mal necessário.

Assim, os achados desta pesquisa corroboram a necessidade de atentar para outras dimensões do envelhecimento, sem ter a pretensão de desconsiderar as dimensões biológicas dessa etapa da vida, mas procurar capturar os sentidos dessa idade cronológica, os significados atribuídos e como tudo isso contribui para o modo como os idosos se percebem em suas individualidades, tecidas em redes sociais e perpassadas por dimensões culturais.

react to them? Qualitative analysis of interviews with patients. Fam Pract. 2006; 23(1):80-87.

4. Schlomann P, Schmitke J. Lay beliefs about hypertension: An interpretive synthesis of the qualitative research. J Am Acad Nurse Pract. 2007; 19(7):358-367.

5. Bane C, Hughes CM, Cupples ME, McElnay JC. The journey to concordance for patients with hypertension: a qualitative study in primary care. Pharm World Sci. 2007; 29(5): 534-540. 
6. Guareschi NMF, Bruschi ME, organizadores. Psicologia social nos Estudos Culturais. Petrópolis,RJ: Vozes; 2003.

7. Hall S. A centralidade da cultura: notas sobre as revoluções culturais do nosso tempo. Educação e Realidade. 1997; 22(2):15-46.

8. Foucault M. O Sujeito e o Poder. In: Dreyfus H, Rabinow P. Michel Foucault, uma trajetória filosófica: para além do estruturalismo e da hermenêutica. Rio de Janeiro: Forense Universitária; 1995. p.231-249.

9. Alvarenga MRM, Oliveira MAC, Domingues MAR, Amendola F, Faccenda O. Social support networks for elderly patients attended by Family Health teams. Ciênc. saúde coletiva. 2011; 16(5):2603-611.

10. Fernandes MGM. Papeis sociais de gênero na velhice: o olhar de si e do outro. Rev Bras Enferm. 2009; 62(5): 705-10.

11. Hall S. A identidade cultural na pós-modernidade. 10a ed. Rio de Janeiro: DP\&A; 2005.

12. Debert GG. Pressupostos da reflexão antropológica sobre a velhice. In: Debert GG, organizadora. Textos Didáticos: Antropologia e Velhice. 2. ed. Campinas, SP: IFCH/UNICAMP; 1998. p.7-28.

13. Tavares SS. "O que rima com idade? "Identidade e sociabilidade na velhice em tempos de transição. Campinas, SP: Alínea; 2005. p. 101-10.

14. Fernandes MGM, Garcia LG. O corpo envelhecido na percepção de homens idosos. Rev Bras Enferm. 2011; 64(3): 472-77.

15. Gusmão NMM. Infância e Velhice: desafios da multiculturalidade. In: Gusmão NMM, organizadora. Infância e velhice: pesquisa de ideias. Campinas, SP: Alínea; 2003. p.15-32.
16. Alves PC. A Experiência da Enfermidade: Considerações teóricas. Cad Saúde Pública. 1993; 9(3): 263-271.

17. Souza AC, Lopes MJM. Práticas terapêuticas entre idosos de Porto Alegre: uma abordagem qualitativa. Rev Esc Enferm USP. 2007; 41(1):51-56.

18. Renovato RD, Dantas AO. Percepção do paciente hipertenso sobre o processo saúde-doença e a terapêutica medicamentosa. Infarma. 2005; 17(3/4): 72-75.

19. Hansson Scherman M, Löwhagen O. Drug compliance and identity: reasons for noncompliance. Experiences of medications from persons with asthma/allergy. Patient Educ Couns. 2004; 54(1):3-9.

20. Sale JEM, Gignac M, Hawker G. How "bad” does the pain have to be? A qualitative study examining adherence to pain medication in older adults with osteoarthritis. Arthritis Rheum. 2006; 55(2):272-78.

21. Wong WKT, Ussher J. How do subjectivelyconstructed meanings ascribed to anti-hiv treatments affect treatment-adherent practice? Qual Health Res. 2008; 18(4): 458-468.

22. Ferreira J. A saúde em comprimidos: influências socioculturais na interpretação de sintomas e terapias medicamentosas em uma vila de classe popular de Porto Alegre. Saúde em Debate. 2001; 25(59):67-72.

23. Renovato RD, Trindade MF. Atenção Farmacêutica na Hipertensão Arterial em uma farmácia de Dourados, Mato Grosso do Sul. Infarma. 2004; 16(11/12): 49-55.

24. Lumme-Sandt K, Virtanen P. Older people in the field of medication. Sociol Health Illn. 2002; 24(3):285-304. 